\title{
A STUDY ON FACTORS AFFECTING THE CONSUMERS PERCEPTION TOWARDS MODE OF BUYING PACKED TENDER COCONUT WATER IN INDIA
}

\author{
SHRUTHI GADHE ${ }^{1} \&$ ADITI MATHUR ${ }^{2}$ \\ ${ }^{I}$ Ph.D Scholar, Institute of Agri Business Management, SKRAU, Bikaner \\ ${ }^{2}$ Assistant Professor, Institute of Agri Business Management, SKRAU, Bikaner
}

\begin{abstract}
Packed coconut water is a byproduct of raw tender coconut which is gaining popularity in the present days. There are two modes of purchasing packed tender coconut water they are offline such as supermarkets, Hypermarkets, Grocery stores etc and online stores are through different sites such as Amazon, Bigbasket, Company websites. Different consumers have different perception towards the mode of buying. The study is conducted in potential market areas in the country to know the consumer perception towards factors affecting the mode of buying packed tender coconut water. The results show that important factor that affects the consumers to purchase in offline mode is the myth of touch feel and the important factor which affects the consumers to purchase online mode is Time.

KEYWORDS: Coconut Water, Offline, Online, Perception \& Consumers
\end{abstract}

Received: Dec 01, 2019; Accepted: Dec 20, 2019; Published: Dec 30, 2019; Paper Id: IJASRDEC201918

\section{INTRODUCTION}

Coconut Water is natural glucose which is used from ancient times and is considered a natural soft drink. Coconut water is a liquid that we can get from the fruit of coconut in the early maturity stage. Coconut water is mostly consumed in tropical areas in order to overcome the hot climatic conditions and coconut water acts as a refreshing drink because of its cool nature. Coconut water is considered a super natural drinkbecause it filled with many nutrients, vitamins, natural oxides and nutrients which is required to boost immunity. Coconut waterconsists of natural sugar agents so no need to add additional sugar in it like any other fruit juices as it is the early form of coconut fruit so at present doctors are prescribing coconut water as a health promoting agent.

There is an increasing demand for packaged coconut water for a few reasons: Consumption is already high, Food safety is a major concern, Healthy is trendy, and it's all about being natural.The coconut development board is currently considering increasing that number to 25 percent, the organized sector of tender coconut producers are slowly increasing. Tapping further into the health market there is a demand for diversification beyond just flavored varieties. It can be treated as a healthy alternative to sugary soft drinks for kids and adults.

\section{METHODOLOGY}

\section{Objective: Factors Affecting the Perception of Mode of Buying for Packed Tender Coconut Water}

Factors that contributed to the perception of mode of buying packed tender coconut water are identified from the consumers during pilot study. They are:

- Time 
- Availability

- Awareness

- $\quad$ Easy to purchase

- Offers

- Myth of touch feel

- $\quad$ Easy to compare with other brands

- Complete information regarding the product

- $\quad$ price

To find out the factors affecting the perception, factor analysis was done for consumer's responses, using principal component extraction method with varimax rotation, to explain the variance.

$$
Z_{i}=A_{i} 1 X_{1}+A_{i} 2 X_{2}+A_{i} 3 X_{3}+----------------------------+A_{i} P X p+V_{i} U_{i}
$$

Where,

○ $\quad Z_{i}=i$ th standardized variable

$\circ \quad \mathrm{A}_{\mathrm{ij}}=$ standardized multiple regression coefficient of variable $\mathrm{i}$ on common factor $\mathrm{j}$

- $. \mathrm{X}=$ Common factor

- $V_{i}=$ standardized regression coefficient of variable $i$ on unique factor $i$

○ $\mathrm{U}_{\mathrm{i}}=$ the unique factor for variable $\mathrm{i}$

○ $\mathrm{m}=$ number of common factors

\section{RESULTS AND DISCUSSIONS}

The objective is to know the affecting factors of consumer's perception towards packed tender coconut water while buying through online or offline mode. Factor analysis is used for analysis separately for offline mode and online mode. To analyze the data factors affecting the perception of mode of buying were identified based on pilot study and the factors coated are time, availability, awareness, easy to purchase, offers, myth of touch feel, easy to compare with other brands, price.

Factors Affecting the Perception of offline Mode Buying of Packed Tender Coconut Water

Table 1: Total Variance Explained

\begin{tabular}{|c|c|c|c|c|c|c|}
\hline \multirow{2}{*}{ Component } & \multicolumn{3}{|c|}{ Eigenvalues } & \multicolumn{3}{c|}{ Rotation Sums of Squared Loadings } \\
\cline { 2 - 7 } & Total & \% of Variance & Cumulative \% & Total & \% of Variance & Cumulative \% \\
\hline 1 & 2.753 & 30.593 & 30.593 & 2.602 & 28.916 & 28.916 \\
\hline 2 & 2.212 & 24.581 & 55.174 & 2.325 & 25.835 & 54.751 \\
\hline 3 & 1.149 & 12.770 & 67.945 & 1.187 & 13.194 & 67.945 \\
\hline 4 & .932 & 10.360 & 78.305 & & & \\
\hline 5 & .748 & 8.313 & 86.618 & & & \\
\hline 6 & .510 & 5.662 & 92.280 & & & \\
\hline 7 & .423 & 4.702 & 96.982 & & & \\
\hline
\end{tabular}


Mode of Buying Packed Tender Coconut Water in India

\begin{tabular}{|c|c|c|c|c|c|c|}
\hline 8 & .155 & 1.728 & 98.710 & & & \\
\hline 9 & .116 & 1.290 & 100.000 & & & \\
\hline
\end{tabular}

Table 1 indicates determining the number of factors extracted for the purpose, the basic method followed here is to select those components which have Eigen-values greater than one. The first factor is 28.916 per cent of variability. The second factor is 25.835 per cent of the variability and the first two factors, in combination, can be 54.751 per cent of the variability. The third factor can explain alone 13.194 per cent of the total variability and the three factors, in combination, can explain 67.945 per cent of the total variability.

Table 2: Rotated Component Matrix ${ }^{a}$

\begin{tabular}{|l|c|c|c|}
\hline \multirow{2}{*}{} & \multicolumn{3}{|c|}{ Component } \\
\cline { 2 - 4 } & $\mathbf{1}$ & $\mathbf{2}$ & $\mathbf{3}$ \\
\hline Time & .191 & -.766 & .068 \\
\hline Availability & .006 & .917 & .158 \\
\hline Awareness & -.023 & .912 & .067 \\
\hline Easytopurchase & .230 & .107 & .753 \\
\hline Offers & .895 & -.083 & .111 \\
\hline Mythoftouchfeel & .918 & -.070 & .082 \\
\hline Easytocomparewithotherbrands & .796 & .125 & -.209 \\
\hline Completeinformationbeforepurchase & .426 & -.164 & -.013 \\
\hline Price & .230 & -.010 & -.723 \\
\hline Source: Researchers Computation & & \\
\hline
\end{tabular}

Table 2 shows that Varimax rotation was applied for the selected 9 attributes. The factor loadings of the 9 variables were then observed and variables were clubbed into three factors. For the purpose of interpretation, each factor was composed of variables with factor loading 0.50 or higher on that factor.

\section{Interpretations}

From the above, it can be concluded that myth of touch feel of the product is the major factor that affect consumer's perception to buy in offline mode. Availability, Awareness, Offers, Easy to compare with other brands directly and easy to purchase the product are the factors that influence the consumers' perception to buy in offline mode.

b) Factors Affecting the Perception of Online Mode of Buying of Packed Tender Coconut Water

Table 3: Total Variance Explained

\begin{tabular}{|c|c|c|c|c|c|c|}
\hline \multirow{2}{*}{ Component } & \multicolumn{3}{|c|}{ Eigen Values } & \multicolumn{3}{c|}{ Rotation Sums of Squared Loadings } \\
\cline { 2 - 7 } & Total & \% of Variance & Cumulative \% & Total & \% of Variance & Cumulative \% \\
\hline 1 & 2.144 & 23.819 & 23.819 & 1.876 & 20.839 & 20.839 \\
\hline 2 & 1.804 & 20.047 & 43.866 & 1.821 & 20.230 & 41.070 \\
\hline 3 & 1.483 & 16.474 & 60.340 & 1.734 & 19.270 & 60.340 \\
\hline 4 & .924 & 10.265 & 70.604 & & & \\
\hline 5 & .806 & 8.959 & 79.564 & & & \\
\hline 6 & .698 & 7.752 & 87.316 & & & \\
\hline 7 & .612 & 6.796 & 94.112 & & & \\
\hline 8 & .376 & 4.174 & 98.286 & & & \\
\hline 9 & .154 & 1.714 & 100.000 & & & \\
\hline
\end{tabular}


Table 3 indicates determining the number of factors extracted for the purpose, the basic method followed here is to select those components which have Eigen-values greater than one.The first factor can alone20.839 per cent of the variability, the second factor can explain 20.230 per cent of the variability and the first two factors, in combination, can explain 41.070 per cent of the variability. The third factor can explain alone 19.270 per cent of the variability and the three factors, in combination, can explain 60.340 per cent of the variability.

Table 4: Rotated Component Matrix ${ }^{\mathrm{a}}$

\begin{tabular}{|l|c|c|c|}
\hline \multirow{2}{*}{} & \multicolumn{3}{|c|}{ Component } \\
\cline { 2 - 4 } & $\mathbf{1}$ & $\mathbf{2}$ & $\mathbf{3}$ \\
\hline Time & .944 & -.030 & .131 \\
\hline Availability & .941 & -.056 & .079 \\
\hline Awareness & .171 & .224 & .509 \\
\hline Easytopurchase & -.031 & .821 & -.024 \\
\hline Offers & .137 & .837 & -.107 \\
\hline Mythoftouchfeel & -.200 & -.573 & .137 \\
\hline Easytocomparewithotherbrands & .006 & .243 & -.589 \\
\hline Completeinformationbeforepurchase & -.001 & .058 & .722 \\
\hline Price & .100 & -.010 & .744 \\
\hline Source: Researchers Computation & & \\
\hline
\end{tabular}

Table 4 shows that Varimax rotation was applied for the selected nine attributes. The factor loadings of the nine variables were then observed and variables were clubbed into five factors. For the purpose of interpretation, each factor was composed of variables with factor loading 0.50 or higher on that factor.

\section{Interpretations}

From the above, it can be concluded that Time is the major factor that affect consumer's perception to buy in online mode. Availability of the product, Offers provided by online sites, easy way to purchase, price, complete information regarding the product before purchase are the factors that influence the consumer's perception to buy in online mode.

\section{CONCLUSIONS}

From the study of both factors affecting the mode of offline buying and online buying, it is stated that myth of touch feel of the product is the major factor which affects consumer's perception to buy in offline mode and Time is the major factor which affects consumer's perception to buy in online mode

\section{REFERENCES}

1. Anojan, V., and Subaskaran, T. 2015. Consumers Preference and Consumers Buying Behavior on Soft Drinks: A Case Study in Northern Province of Sri Lanka. Global Journal of Management and Business Research, 15(2), 11-37.

2. Espiritu, Jo A. "The Livelihood Resources, Practices and Values of Aetas in Mid-Baytan, Zambales, Philippines: Implications to Education and Community Development." International Journal of Humanities and Social Sciences (IJHSS) 7.6 (2018): 3754.

3. Santos Aline Bravim, Bottoni Sharlayne de Souza, Silva Daniela Alvas, and Silva Erika Madeira Moreira da, 2017. Study of the consumers of Ready -to- drink juices and Fruit Nectars. Food Science Technol, Campinas. 10(1), 57-78.

4. Reddy, T. Balarami. "Mechanical performance of green coconut fiber/HDPE composites by using flexural strength." International Journal of Mechanical Engineering (IJME), 3 (1), 5366 (2014). 
Mode of Buying Packed Tender Coconut Water in India

5. Salleh, M. M. B. H., et al. "Mechanical Properties of Coconut Carbon Fibre/Epoxy Composite Material." International Journal of Mechanical Engineering (IJME) 2.3: 55-62.

6. OFFIA OLUA, B. I., QC ELUWA, and C. ABUAJAH. "Incorporation of Papain into Ice Cream: Impact on Pawpaw (Carica Papaya) Ice Cream Quality." IASET: International Journal of Biology, Biotechnology and Food Science (IASET: IJBBFS) 1.1: 7-22. 
